\title{
Erratum to: The well-being of children impacted by a parent with cancer: an integrative review
}

\author{
Julia N. Morris ${ }^{1} \cdot$ Angelita Martini $^{1}$ • David Preen ${ }^{1}$
}

Published online: 7 May 2016

(C) Springer-Verlag Berlin Heidelberg 2016

Erratum to: Support Care Cancer

DOI 10.1007/s00520-016-3214-2

The published version of this article contains errors under 'Method' (page 2). In three instances, the total number of studies reviewed should read forty-nine (49), not fifty (50). Also, the number of quantitative studies considered was 25 , not 26 .

The online version of the original article can be found at http://dx.doi.org/ 10.1007/s00520-016-3214-2.

\footnotetext{
Julia N. Morris

julia.morris@uwa.edu.au

Angelita Martini

angelita.martini@uwa.edu.au

David Preen

david.preen@uwa.edu.au

1 Centre for Health Services Research, School of Population Health, The University of Western Australia, 35 Stirling Hwy,

Crawley, WA 6009, Australia
} 